\title{
Deracemization and Stereoinversion of Alcohols Using Two Mutants of Secondary Alcohol Dehydrogenase from Thermoanaerobacter pseudoethanolicus
}

\author{
Sodiq A. Nafiu, ${ }^{[a]}$ Masateru Takahashi, ${ }^{[b]}$ Etsuko Takahashi, ${ }^{[b]}$ Samir M. Hamdan, ${ }^{[b]}$ and Musa M. \\ Musa ${ }^{*}[a]$
}

[a] S. A. Nafiu, Prof. M. M. Musa

Chemistry Department

King Fahd University of Petroleum and Minerals

Dhahran, 31261, KSA

E-mail:musam@kfupm.edu.sa

http://faculty.kfupm.edu.sa/CHEM/musam/index.html

[b] Dr. M. Takahashi, E. Takahashi, Prof. S. M. Hamdan

Division of Biological and Environmental Sciences and Engineering

King Abdullah University of Science and Technology

Thuwal, 23955-6900, KSA

Supporting information for this article is given via a link at the end of the document

\begin{abstract}
We developed a one-pot sequential two-step deracemization approach for alcohols using two mutants of Thermoanaerobacter pseudoethanolicus secondary alcohol dehydrogenase (TeSADH). This approach relies on consecutive nonstereospecific oxidation of alcohols and stereoselective reduction of their prochiral ketones using two mutants of TeSADH with poor and good stereoselectivities, respectively. More specifically, W110G TeSADH enables a non-stereospecific oxidation of alcohol racemates to their corresponding prochiral ketones, followed by W110V TeSADH-catalyzed stereoselective reduction of the resultant ketone intermediates to enantiopure (S)-configured alcohols in up to $>99 \%$ enantiomeric excess. A heat treatment after the oxidation step was required to avoid the interference of the marginally stereoselective W110G TeSADH in the reduction step; this heat treatment was eliminated by using sol-gel encapsulated W110G TeSADH in the oxidation step. Moreover, this bi-enzymatic approach was implemented in the stereoinversion of $(R)$-configured alcohols, and $(S)$-configured alcohols with up to $>99 \%$ enantiomeric excess were obtained by this Mitsunobu-like stereoinversion reaction.
\end{abstract}

\section{Introduction}

Optically active alcohols are important building blocks for chemicals that play key roles in pharmaceutical, agrochemical, and food industries. ${ }^{[1,2]}$ Kinetic resolution $(\mathrm{KR})$ is the commonly used industrial method for the synthesis of enantiomerically pure alcohols. ${ }^{[3,4]}$ However, a maximum yield of $50 \%$ with high enantioselectivity is a challenging drawback associated with this approach. An optimum alternative that overcomes this hitch is to obtain enantiopure alcohols via deracemization, which ensures up to $>99 \%$ yields of enantiopure alcohols from their racemates. Among the deracemization strategies discussed in the literature are cyclic deracemization, dynamic kinetic resolution, stereoinversion and enantioconvergence. ${ }^{[5]}$ Although enantiopure alcohols can be produced in high yields by asymmetric reduction of their prochiral ketones ${ }^{[6]}$ this approach is not optimal since ketones are less naturally abundant than alcohols; hence, quantitative production of enantiopure alcohols using deracemization approaches is more attractive than asymmetric reduction of their ketones.

Deracemization strategies of alcohols using chemical catalysis ${ }^{[7]}$ and chemoenzymatic approaches[ 8 ] have been reported. However, biocatalysis-based deracemization reactions are preferable due to the following reasons: firstly, they possess high stereo-, regio- and chemoselectivities, secondly, they can overcome challenges such as profitability and sustainability in fine chemical industries, ${ }^{[9,10]}$ thirdly, they are environmentally benign catalysts, and fourthly, they work effectively under mild conditions, which eliminates side products that could result from undesirable isomerization or epimerization. Therefore, several methods of enzymatic deracemization of alcohols have been reported. However, these methods use whole cells, ${ }^{[11]}$ which complicates the elucidation of deracemization mechanism, thus restricts further developments of these approaches. Alternatively, they use complicated systems that comprise multiple enzymes, ${ }^{[12]}$ which raises problems associated with compatibility among involved enzymes and with the reaction conditions.

Biocatalytic asymmetric redox reactions mediated by alcohol dehydrogenases (ADHs) is an important class of reactions. Secondary ADH from Thermoanaerobacter pseudoethanolicus (TeSADH, EC 1.1.1.2), a nicotinamide-adenine dinucleotide phosphate $\left(\mathrm{NADP}^{+}\right)$-dependent $A D H$, is a robust $A D H$, and thus an attractive choice as a biocatalyst. ${ }^{[13,14]}$ Our group previously developed a one-pot two-step deracemization approach for secondary alcohols by employing a single mutant of TeSADH. ${ }^{[15]}$ This approach relies on non-stereospecific oxidation of alcohol racemates to their corresponding ketones, which in turn followed by an enantioselective reduction employing the same enzyme (Scheme 1). The desired tuned enantioselectivities of the redox reactions was accomplished by controlling the concentrations of acetone and 2-propanol co-substrates in the oxidation and reduction reactions, respectively. Enantiopure alcohols were obtained in $20 \%$ to $87 \%$ ee when W110A TeSADH was used and $47 \%$ to $>99 \%$ when W110G TeSADH was used. 


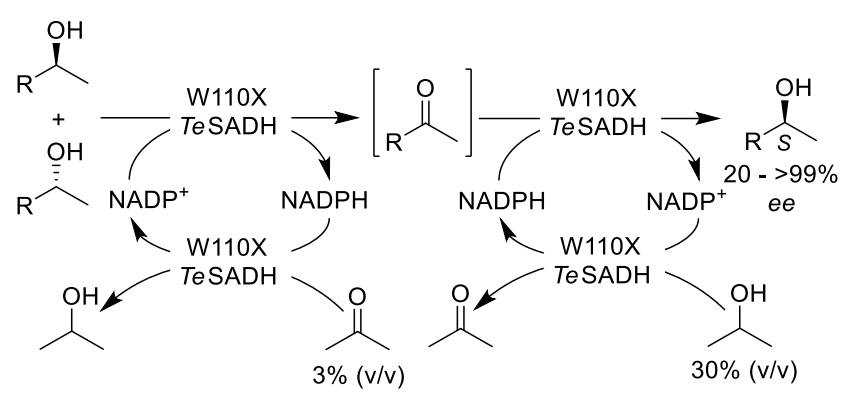

Scheme 1. Scheme 1. One-pot two-step deracemization of alcohols using a single TeSADH mutant. $\mathrm{X}=\mathrm{G}$ or $\mathrm{A}$. $\mathrm{R}=$ Phenyl-ring-containing substituents.

In an effort to improve the enantiopurities of the alcohols obtained by this method, we explored the use of two mutants of TeSADH that vary in their enantioselectivities, one for the nonstereospecific oxidation step and the other for the stereoselective reduction. Herein, we report the implementation of this approach using W110G and W110V TeSADH mutants in the oxidation and reduction steps, respectively, to accomplish deracemization of racemic alcohols and stereoinversion of $(R)$-alcohols.

\section{Results and Discussion}

The medium enantioselectivities encountered with few substrates in the single enzymatic deracemization, shown in Scheme 1, could be explained by the incomplete depletion of $(R)$-alcohol in the oxidation reaction or the selectivity mistakes that could be encountered in the second step by virtue of using a marginally selective enzyme, or both. To improve the enantioselectivity of this sequential deracemization approach, we conducted the oxidation step using W110G TeSADH, which is known for its marginal enantioselectivity with phenyl-ring-containing secondary alcohols. ${ }^{[16]}$ This approach should ensure the maximum depletion of both enantiomers of alcohol substrates. We selected 1-phenyl2-propanol [(rac)-1c] because it was deracemized with low efficiency using W110G or W110A TeSADHs in the previously reported single enzymatic deracemization approach. [15] Quantitative conversion of (rac)-1c to the corresponding ketone was achieved; this step was carried out using acetone (3\%, v/v), which was used as a co-substrate and a co-solvent at the same time. Upon full conversion of (rac)-1c to its ketone using W110G TeSADH, a heat treatment to deactivate this mutant was applied before proceeding with the enantioselective reduction step; this step was necessary to prevent the intervention of W110G TeSADH in the reduction step. W110V TeSADH was used for the enantioselective reduction step because it was reported to have high enantioselectivity in the reduction of phenyl-ring-containing ketones. ${ }^{[16]}$ The second step was affected by using 2-propanol $(5 \%, v / v)$. Using these sequential redox reactions, (rac)-1c was deracemized to obtain (S)-1c in $95 \%$ ee, compared to $47 \%$ ee when W110G TeSADH was used as a sole catalyst. This significant improvement in the deracemization efficiency encouraged us to implement this deracemization, using W110G and W110V TeSADH, on other phenyl-ring-containing alcohols. The utilization of two mutants of $T e S A D H$ is advantageous since both mutants are from the same enzyme and thus compatibility is not an issue.

Under the aforementioned deracemization conditions and using two mutants of TeSADH, (rac)-4-(4'-hydroxyphenyl)-2-butanol [(rac)-1a] was deracemized to obtain (S)-1a in >99\% ee. (S)-4-(4'Methoxyphenyl)-2-butanol [(S)-1b] was obtained from its racemate in $98 \%$ ee (Table 1), compared to $72 \%$ ee and $87 \%$ ee when the single enzymatic approach was employed using W110G or W110A mutants of TeSADH, respectively. (S)-4-Phenyl-2butanol $[(S)$-1d] and (S)-1-phenyl-2-butanol [(S)-1e] were also obtained in $>99 \%$ ee using W110G and W110V TeSADHs. In all cases, the percent of remaining ketone intermediate after the reduction step was less than $0.5 \%$. The currently reported bienzymatic deracemization approach gave better results in terms of ee than the previously reported single enzymatic approach developed in our laboratory. ${ }^{[15]}$

Table 1. Bi-enzymatic deracemization of racemic phenyl-ring containing secondary alcohols. ${ }^{[a]}$

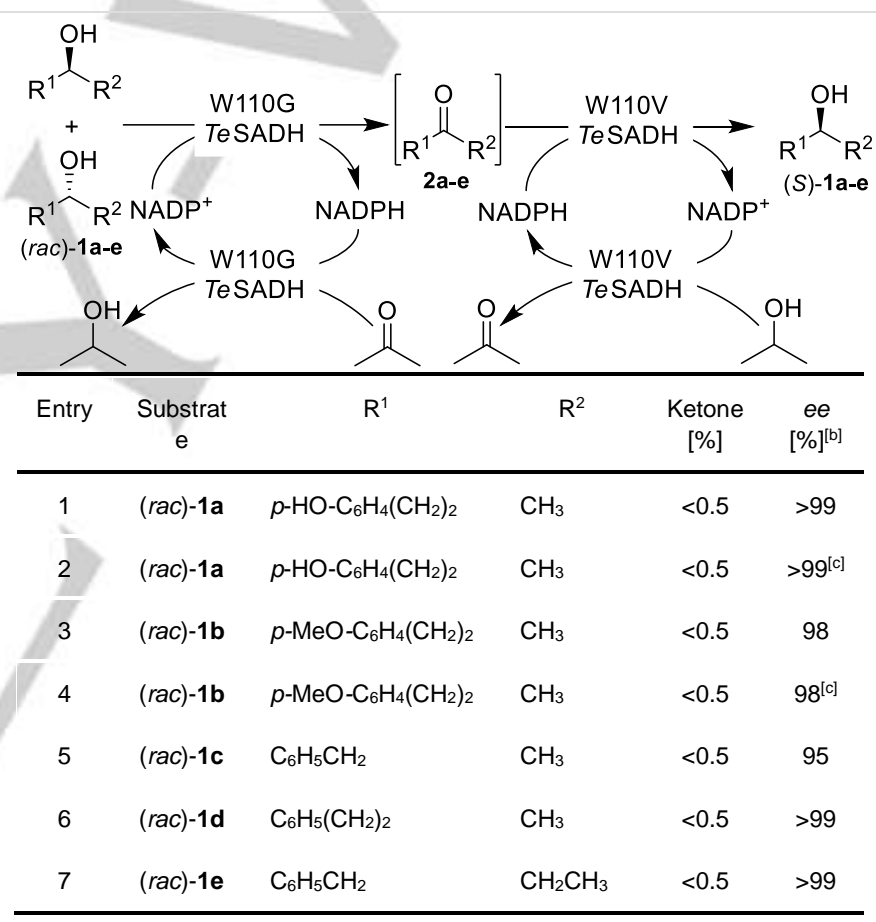

[a] Unless stated, oxidation reactions were performed by using racemic alcohol [(rac)-1a-e (0.03 mmol)], W110G TeSADH (0.2 mg), NADP ${ }^{+}(1.0 \mathrm{mg})$, and acetone $(3 \%, v / v)$; reduction reactions were performed by using $\mathrm{W} 110 \mathrm{~V}$ TeSADH $(0.2 \mathrm{mg})$ and 2-propanol $(5 \%, \mathrm{v} / \mathrm{v})$. [b] The \% ee of the acetate ester derivative of the product was determined by using GC with a chiral stationary phase. [c] Oxidation reactions were performed using sol-gel encapsulated W110G TeSADH.

In order to overcome the heat treatment to inactivate the enzyme used in the oxidation reaction, we used sol-gel encapsulated W110G TeSADH to perform the oxidation step. ${ }^{[17]}$ Encapsulation of enzymes in porous sol-gel offers unique properties such as large surface area and porosity. ${ }^{[18]}$ Affecting the oxidation of $(\mathrm{rac}) \mathbf{- 1 a}$ and $(\mathrm{rac})$-1 $\mathbf{1 b}$ by sol-gel-encapsulated W110G TeSADH enabled the complete oxidation to their corresponding ketones. The reduction of the intermediate ketones was then followed by using free W110V TeSADH after removal of the sol-gel W110G TeSADH, thus avoiding the heat treatment after the oxidation step. It was observed that deracemization of 
these two substrates using the sol-gel encapsulated enzyme (entries 2 and 4 of Table 1) gave the same results in terms of ee and percentage recovery when compared to the results obtained by the free enzymatic deracemization approach. This sol-gel encapsulated enzymatic deracemization approach could enable deracemization of heat labile racemic alcohols without decomposition. Moreover, it allows for enzyme recycling.

The ability of W110G TeSADH to deplete both enantiomers of alcohols in the deracemization reactions described above indicates that this approach can be used in stereoinversion of $(R)$ alcohols, the slightly undesired enantiomer for W110G TeSADH, (i.e., Mitsunobu-like reaction). Thus, we extended this approach to conduct stereoinversion reactions of $(R)-\mathbf{1 a},(R)-\mathbf{1 c}$, and $(R)-\mathbf{1 d}$ W110G TeSADH-catalyzed oxidation of $(R)$-alcohols, followed by W110V TeSADH-catalyzed reduction of resultant prochiral ketones offered $(S$ )-alcohols in high ee's (up to $>99 \%$ ), as shown in Table 2. Whereas, (S)-1c and (S)-1d were previously obtained in $33 \%$ ee and $80 \%$ ee, respectively, using a single enzymatic stereoinversion approach for their $(R)$-alcohols catalyzed by W110G TeSADH. ${ }^{[19]}$ Stereoinversion of undesired enantiomers that result from transformations such as KR is economically and environmentally pivotal in industrial sector. The currently reported environmentally benign stereoinversion reaction of alcohols offers an alternative to the well-known Mitsunobu stereoinversion reaction, which, although known for its poor atom efficiency that is evident by the production of stoichiometric amounts of hydrazine and phosphine oxide by-products, still widely used. ${ }^{20]}$

Table 2. Bi-enzymatic stereoinversion of $(R)$-configured phenyl-ring containing secondary alcohols. ${ }^{[a]}$

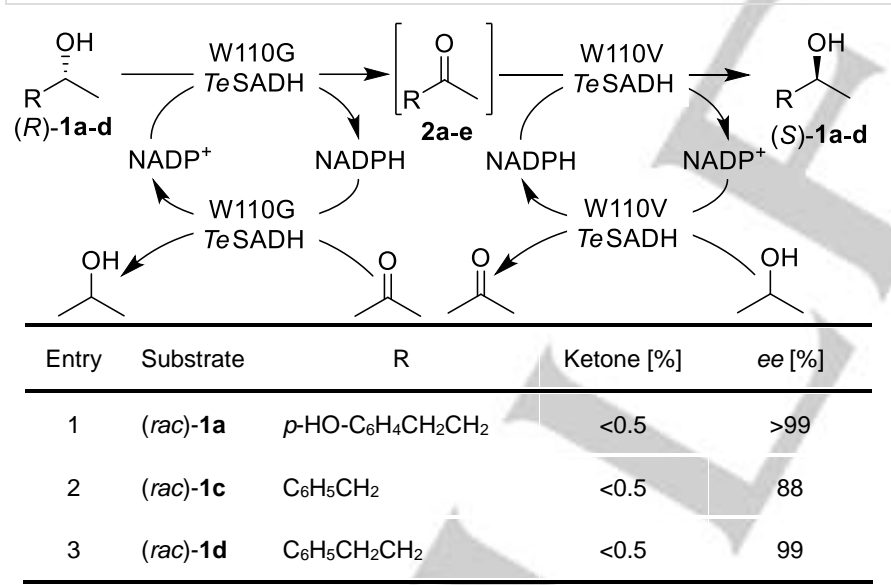

[a] Unless stated, oxidation reactions were performed using $(R)$-alcohol $(0.03$ $\mathrm{mmol}), \mathrm{W} 110 \mathrm{G} \mathrm{TeSADH}(0.4 \mathrm{mg})$, and $\mathrm{NADP}^{+}(1.0 \mathrm{mg})$ in $970 \mu \mathrm{L} \mathrm{Tris}-\mathrm{HCl}$ buffer solution $(50 \mathrm{mM}, \mathrm{pH} 8.0)$ containing acetone $(3 \%, \mathrm{v} / \mathrm{v})$, at $50{ }^{\circ} \mathrm{C}$ with shaking at $180 \mathrm{rpm}$ for $48 \mathrm{~h}$; reduction reactions were performed using 2 propanol $(5 \%, \mathrm{v} / \mathrm{v}), \mathrm{W} 110 \mathrm{~V}$ TeSADH $(0.2 \mathrm{mg})$ and $\mathrm{NADP}^{+}(1.0 \mathrm{mg})$ at $50^{\circ} \mathrm{C}$ with shaking at $180 \mathrm{rpm}$ for $24 \mathrm{~h}$. [b] The \% ee of the stereoinversion products was determined using GC with a chiral stationary phase.

The high efficiencies of the currently reported approach in deracemization of racemic alcohols and in stereoinversion of $(R)$ alcohols, when compared to those obtained using a single mutant of TeSADH, justifies the use of two mutants especially that the two mutants are for the same enzymes. Future efforts should be devoted towards the design of new ADH mutants that exhibit expanded substrate scopes and tuned stereoselectivities to enable further improvement of the currently reported approach.

\section{Conclusion}

In conclusion, the use of a marginally stereoselective W110G mutant of TeSADH for the oxidation of alcohol racemates and the highly stereoselective W110V TeSADH for the reduction of the corresponding ketones enabled a one pot deracemization of secondary alcohols in two steps. This approach was used in deracemization of the phenyl-ring-containing racemic alcohols in high efficiencies (up to $>99 \%$ ee). It was also employed in the stereoinversion of $(R)$-configured alcohols to give up to $>99 \%$ ee of $(S)$-configured alcohols. This approach is an attractive one for industrial production of enantiopure alcohols from their racemates because it uses an environmentally benign robust catalyst.

\section{Experimental Section}

General

Sodium borohydride, NADP+, $($ rac $)$-1c, $(R)-\mathbf{1 c},(S)-\mathbf{1 c},(R)-\mathbf{1 d},(S)-\mathbf{1 d}, \mathbf{2 a}$ $\mathbf{2 b}, \mathbf{2 d}$, and $\mathbf{2 e}$ were purchased from commercial sources and used without further treatment. Whereas, (rac)-1a, (rac)-1 b, (rac)-1d and (rac)-1e were prepared from their corresponding ketones $\mathbf{2 a}, \mathbf{2 b}, \mathbf{2 d}$, and $\mathbf{2 e}$, respectively, using sodium borohydride. ${ }^{\left[{ }^{[1]}\right.}$ However, $(R)-\mathbf{1 a}$ was prepared by Candida antarctica lipase B (CaLB)-catalyzed KR of (rac)-1a. [16] All Gas Chromatography (GC) analyses were conducted using a capillary gas chromatography (GC) loaded with HP chiral-20B column $(30 \mathrm{~m}, 0.32 \mathrm{~mm}$ [i.d.], $0.25 \mu \mathrm{m}$ film thickness) using Helium as the carrier gas with a flame ionization detector. NMR spectra were recorded on a JOEL JNM-LA500 FT NMR at $500 \mathrm{MHz}\left({ }^{1} \mathrm{H}\right)$ and at $125 \mathrm{MHz}\left({ }^{13} \mathrm{C}\right)$ at room temperature, using deuterated chloroform $\left(\mathrm{CDCl}_{3}\right)$ peak as an internal standard.

Gene Expression and purification of W110G and W110V TeSADH mutants

W110G and W110V TeSADHs were expressed and purified as reported previously. $\left[15^{, 22]}\right.$

\section{Deracemization of secondary alcohols}

Alcohol racemates [(rac)-1a-e, $0.03 \mathrm{mmol}]$ were added into a mixture containing W110G TeSADH $(0.2 \mathrm{mg})$ and NADP+ $(2.0 \mathrm{mg}, 2.7 \mu \mathrm{mol})$ in Tris- $\mathrm{HCl}$ buffer solution $(970 \mu \mathrm{L}, 50 \mathrm{mM}, \mathrm{pH} 8.0)$ and acetone $(30 \mu \mathrm{L}, 0.41$ $\mathrm{mmol}$ ) in a $2.0-\mathrm{mL}$ Eppendorf tube. The mixture was shaken at $50^{\circ} \mathrm{C}$ at $180 \mathrm{rpm}$ for about $24 \mathrm{~h}$ until both enantiomers were oxidized; reactions were monitored by GC. The solution obtained after the oxidation reaction was subjected to heat treatment at $80{ }^{\circ} \mathrm{C}$ for $45 \mathrm{~min}$ to denature any remaining W110G TeSADH. A fresh W110V TeSADH $(0.2 \mathrm{mg})$ followed by 2-propanol ( $50 \mu \mathrm{L}, 0.65 \mathrm{mmol})$ were added to the same reaction vessel, and further subjected to shaking for about $24 \mathrm{~h}$ at $180 \mathrm{rpm}$ at $50^{\circ} \mathrm{C}$. The percent conversion and ee were then evaluated by using a GC loaded with a chiral stationary phase.

\section{Preparation of sol-gel encapsulated W110G TeSADH}

Sol-gel encapsulated W110G TeSADH was prepared with little modification from the previously reported method. ${ }^{[17 a]}$ The Sol was prepared by mixing $2.10 \mathrm{~g}$ of tetramethyl orthosilicate (TMOS), $0.47 \mathrm{~g}$ of distilled water and three drops of $0.05 \mathrm{M} \mathrm{HCl}$. The mixture was mixed thoroughly until a homogeneous phase was achieved. The gels were then processed by adding the previously prepared sol $(1.5 \mathrm{~mL})$ to a solution containing W110G TeSADH and NADP+ in a $15 \mathrm{~mL}$ Eppendorf tube. The W110G TeSADH and NADP ${ }^{+}$were prepared by adding Tris-HCl buffer solution $(50 \mathrm{mM}, \mathrm{pH} 8.0)$ to attain final concentration of 0.43 and 3.0 $\mathrm{mg} \cdot \mathrm{mL}^{-1}$ for the enzyme and coenzyme, respectively. The sol-gel was 
subsequently protected with Parafilm and allowed to stand undisturbed for $48 \mathrm{~h}$ to allow complete formation of a sol-gel encapsulated W110G TeSADH.

\section{Deracemization using sol-gel W110G TeSADH}

Alcohol racemates [ $(\mathrm{rac})-\mathbf{1} \mathbf{a}$ or $(\mathrm{rac})-\mathbf{b}](0.03 \mathrm{mmol})$ were introduced into a mixture of sol-gel encapsulated W110G TeSADH and NADP $+2.0 \mathrm{mg}$, $2.7 \mu \mathrm{mol})$ in Tris- $\mathrm{HCl}$ buffer solution $(970 \mu \mathrm{L}, 50 \mathrm{mM}, \mathrm{pH}$ 8.0) and acetone $(30 \mu \mathrm{L}, 0.41 \mathrm{mmol})$ in a $2.0-\mathrm{mL}$ Eppendorf tube. The mixture was shaken at $50^{\circ} \mathrm{C}$ at $180 \mathrm{rpm}$ for about $24 \mathrm{~h}$ until both enantiomers were oxidized; reactions were monitored by GC. The encapsulated W110G TeSADH was removed from the reaction mixture before W110V TeSADH $(0.2 \mathrm{mg}$ of 4.6 $\mathrm{mg} / \mathrm{mL}$ ) and 2-propanol (50 $\mu \mathrm{L}, 0.65 \mathrm{mmol})$ were added to the same reaction vessel, and further subjected to shaking for about $24 \mathrm{~h}$ at $180 \mathrm{rpm}$ at $50^{\circ} \mathrm{C}$. The resulted organic layers were subjected to drying with $\mathrm{Na}_{2} \mathrm{SO}_{4}$ and further concentrated. The percent recovery and the ee of $(S)$ configured alcohols were subsequently evaluated using a GC equipped with a chiral column.

\section{Stereoinversion of $(\boldsymbol{R})$-configured secondary alcohols}

$(R)$-Configured alcohols $[(R)-\mathbf{1 a},(R)-\mathbf{1 c}$ and $(R)-\mathbf{1 d}, 0.03 \mathrm{mmol}]$ were added into a mixture containing W110G TeSADH $(0.4 \mathrm{mg})$ and NADP ${ }^{+}(2.0$ $\mathrm{mg}, 2.7 \mu \mathrm{mol})$ in Tris- $\mathrm{HCl}$ buffer solution $(970 \mu \mathrm{L}, 50 \mathrm{mM}, \mathrm{pH}$ 8.0) and acetone $(30 \mu \mathrm{L}, 0.41 \mathrm{mmol})$ in a 2.0-mL Eppendorf tube. The mixture was shaken at $50^{\circ} \mathrm{C}$ at $180 \mathrm{rpm}$ for about $36 \mathrm{~h}$ until oxidation reaction was complete; reactions were monitored by GC. The solution obtained after the oxidation reaction was subjected to heat treatment at $80^{\circ} \mathrm{C}$ for $45 \mathrm{~min}$ to denature any remaining W110G TeSADH. A fresh W110V TeSADH $(0.2$ $\mathrm{mg}$ ) followed by 2-propanol $(50 \mu \mathrm{L}, 0.65 \mathrm{mmol})$ were added to the same reaction vessel, and further subjected to shaking for about $24 \mathrm{~h}$ at $180 \mathrm{rpm}$ at $50^{\circ} \mathrm{C}$. The percent conversion and ee were then evaluated by using a GC loaded with a chiral stationary phase.

\section{Determination of enantiomeric excess}

The produced alcohols were converted to their corresponding acetate esters by treatment with two drops of acetic anhydride and three drops of pyridine prior to their analysis by the chiral GC. The following method was used in the GC analysis: Initial oven temperature was $100^{\circ} \mathrm{C}$ for $10 \mathrm{~min}$ to $180^{\circ} \mathrm{C}$ for $20 \mathrm{~min}$ at $5^{\circ} \mathrm{C} / \mathrm{min}$; injector $220^{\circ} \mathrm{C}$, detector $230^{\circ} \mathrm{C}$; and the Helium at $15 \mathrm{~mL} / \mathrm{min}$. The volume injected was $1.0 \mu \mathrm{L}$ with split ratio of $10: 1$.

\section{Determination of absolute configuration of alcohols}

The absolute configurations of the produced alcohols were elucidated by comparing the chiral GC retention time of their acetate derivatives with either their commercially available $(S)$ - or $(R)$-acetate enantiomer or the acetate derivatives of alcohols prepared by W110A TeSADH-catalyzed asymmetric reduction of their ketones, which are reported to produce $(S)$ alcohols, ${ }^{[23]}$ and $(R)$-configured alcohols synthesized by CaLB-catalyzed KR of racemic alcohols.[16]

\section{Acknowledgements}

The authors acknowledge the support provided by the Deanship of Scientific Research (DSR) at King Fahd University of Petroleum and Minerals (KFUPM) for funding this work through project number DF191007. The authors also thank Prof. Claire Vieille, from the Department of Microbiology and Molecular Genetics as well as Biochemistry and Molecular Biology at Michigan State University, for providing the plasmids of TeSADH.
Keywords: Alcohol dehydrogenases $•$ deracemization $•$ redox reaction $\cdot$ stereoinversion $\cdot$ stereoselectivity

[1] W. Kroutil, H. Mang, K. Edegger, K. Faber, Curr. Opin. Chem. Biol. 2004 8, 120-126.

[2] K. Goldberg, K. Schroar, S. Lutz, A. Liese, Appl. Microbiol. Biotechnol. 2007, 76, 237-248.

[3] A. Liese, K. Seelbach, C. Wandrey, Industrial biotransformation, Wiley$\mathrm{VCH}$, Weinheim, $2^{\text {nd }}$ edn, 2006.

[4] U. Bornscheuer, R. Kazlauskas, Hydrolases in Organic Synthesis, WileyVCH, Weinheim, $2^{\text {nd }}$ edn, 2006

[5] Readers are referred to the following reviews on deracemization: a) M. M. Musa, F. Hollmann, F. G. Mutti, Catal. Sci. Technol. 2019, 9, 54875503; b) A. Diaz-Rodriguez, I. Lavandera, V. Gotor, Curr. Green Chem. 2015, 2, 192-211; c) V. Verho, J. E. Bäckvall, J. Am. Chem. Soc. 2015 137, 3996-4009; d) G. A. Applegate, D. B. Berkowitz Adv. Synth. Catal. 2015, 357, 1619-1632; e) M. Rachwalski, N. Vermue and F. P. J. T. Rutjes, Chem. Soc. Rev. 2013, 42, 9268-9282; f) J. H. Lee, K. Han, M. J. Kim and J. Park, Eur. J. Org. Chem. 2010, 999-1015; g) J. Steinreiber K. Faber, H. Griengle, Chem. Eur. J. 2008, 14, 8060-8072.

[6] a) B. T. Cho, Chem. Soc. Rev. 2009, 39, 443-452; b) F. Hollmann, I. W. C. E. Arends, D. Holtmann, Green Chem. 2011, 13, 2285-2313; c) Q.-A Chem, Z.-S. Ye, Y. Duan, Y.-G. Zhou, Chem. Soc. Rev. 2013, 42, 497511; d) F. Hollmann, D. J. Opperman, C. E. Paul Angew. Chem Int. Ed. in press, doi.org/10.1002/anie.202001876.

[7] a) G. R. A. Adair, J. M. Williams, Chem. Commun. 2007, 2608-2609; b) G. R. A. Adair, J. M. Williams, Chem. Commun. 2005, 5578-5579; c) Y Shimada, Y. Miyake, H. Matsuzawa, Y. Nishibayashi, Chem. Asian J. 2007, 2, 393-396.

[8] a) K. Kedziora, A. Diaz-Rodriuez, I. Lavandera, V. Gotor-Fernández, V. Gotor, Green Chem. 2014, 16, 2448-2453; b) D. Méndez-Sánchez, J. Mangas-Sánchez, I. Lavandera, V. Gotor, V. Gotor-Fernández, Chem CatChem 2015, 7, 4016-4020; c) E. Liardo, N. Rios-Lombardia, F. Moris, J. González-Sabin, F. Rebolledo, Eur. J. Org. Chem. 2018, 30313035.

[9] S. M. A. De Wildeman, T. Sonke, H. E. Schoemaker, O. May, Acc. Chem. Res. 2007, 40, 1260-1266.

[10] J. C. Moore, D. J. Pollard, B. Kosjek, P. N. Devine, Acc. Chem. Res 2007, 40, 1412-1419.

[11] a) C. E. Paul, I. Lavandera, V. Gotor-Fernández, W. Kroutil, V. Gotor, ChemCatChem 2013, 5, 3875-3881; b) B. Li, Y. Nie, X. Q. Mu, Y. Xu, J Mol. Catal. B: Enzym. 2016, 129, 21-28; c) S. Venkataraman, A. Chadha, J. Ind. Microbiol. Biotechnol. 2015, 42, 173-180; d) T. Sivakumari, A. Chadha, RSC Adv., 2015, 5, 91594-91600; e) T. Saravanan, R. Selvakumar, M. Doble, A. Chadha, Tetrahedron Asymmetry 2012, 23 1360-1368; f) T. Cazetta, P. J. S. Moran, A. R. Rodrigues, J. Mol. Cat. B: Enzym. 2014, 109, 178-183; g) M.C. Fragnelli, P. Hoyos, D. Romano R. Gandolfi, A. R. Alcantara, F. Molinari, Tetrahedron 2012, 68, 523-528; h) Y.-P. Xue, Y.-G. Zheng, Y.-Q. Zhang, J.-L.-Sun, Z.-Q. Liu, Y.-C. Shen, Chem. Commun. 2013, 49, 10706-10708; i) C. V. Voss, C. C. Gruber W. Kroutil, Angew. Chem. Int. Ed. 2008, 47, 741-745; Angew. Chem. 2008, 120, 753-757.

[12] C. V. Voss, C. C. Gruber, K. Faber, T. Knaus, P. Macheroux, J. Am Chem. Soc. 2008, 130, 13969-13972.

[13] F. O. Bryant, J. Wiegel, L. G. Ljungdahl, Appl. Environ. Microbiol. 1988 54, 460-465.

[14] M. M. Musa, K. I. Ziegelmann-Fjeld, C. Vieille, R. S. Phillips, Org. Biomol. Chem. 2008, 6, 887-892.

[15] I. Karume, M. M. Musa, S. M. Hamdan, M. Takahashi, ChemCatChem 2016, 8, 1459-1463.

[16] J. M. Patel, M. M. Musa, D. A. Rodriguez, D. A. Sutton, V. V. Popik, R S. Phillips, Org. Biomol. Chem. 2014, 12, 5905-5910.

[17] a) M. M. Musa, K. I. Ziegelmann-Fjeld, C. Vieille, J. G. Zeikus, R. S. Phillips, Angew. Chem. 2007, 119, 3151-3154; Angew. Chem. Int. Ed. 2007, 46, 3091-3094; b) L. M. Ellerby, C. R. Nishida, F. Nishida, S. A. Yamanaka, B. Dunn, J. S. Valentine, J. I. Zink, Science 1992, 255, 11131115 
[18] D. Koszelewski, N. Müller, J. H. Schrittwieser, K. Faber, W. Kroutil, J. Mol. Catal. B-Enzym. 2010, 63, 39-44.

[19] M. M. Musa, I. Karume, M. Takahashi, S. M. Hamdan, N. Ullah, ChemistrySelect 2018, 3, 10205-10208.

[20] a) J. S. Carey, D. Laffan, C. Thomson, M. T. Willams, Org. Biomol. Chem. 2006, 4, 2337-2347; b) K. C. K. Swamy, N. N. B. Kumar, E. Balaraman, K. V. P. P. Kumar, Chem. Rev. 2009, 109, 2551-2651.

[21] L. A. Gemal, L. J. Luche, J. Am. Chem. Soc. 1981, 103, 5454-5459.

[22] O. Bsharat, M. M. Musa, C. Vieille, S. A. Oladepo, M. Takahashi, S. M. Hamdan, ChemCatChem 2017, 9, 1487-1493.

[23] M. M. Musa, K. I. Ziegelmann-Fjeld, C. Vieille, J. G. Zeikus, R. S. Phillips, J. Org. Chem. 2007, 7, 451-460. 


\section{WILEY-VCH}

\section{FULL PAPER}

\section{Entry for the Table of Contents}

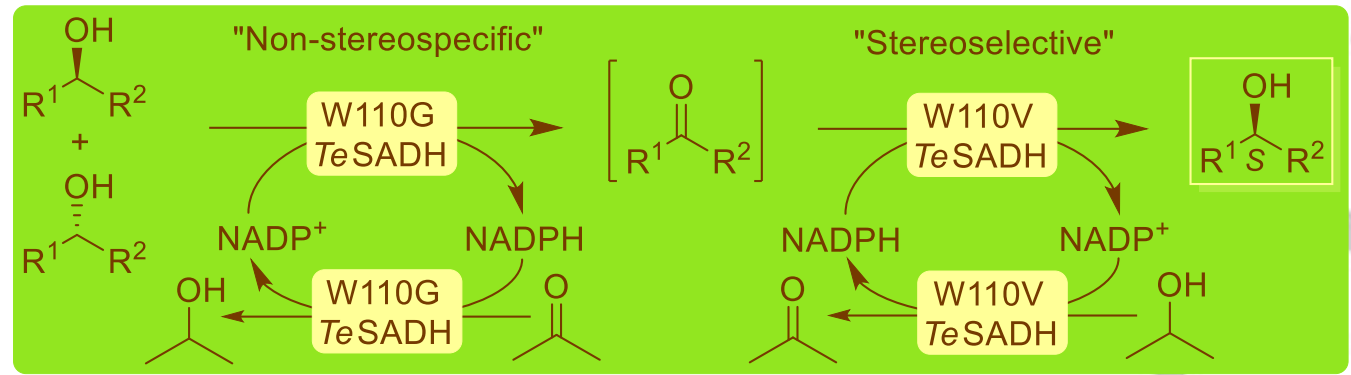

A one-pot two-step deracemization approach for alcohols that uses two mutants of Thermoanaerobacter pseudoethanolicus secondary alcohol dehydrogenase that exhibit different extents of stereoselectivity is reported. This approach is also used in stereoinversion of $(R)$-alcohols (i.e., Mitsunobu-like reaction).

Institute and/or researcher Twitter usernames: KFUPM 